\title{
Management of operational and calendar planning of experimental and serial machine-building production based on the use of petri nets
}

\author{
Dilyara Malikova ${ }^{1 *}$ Evgeny Zhulanov $^{2}$, and Evgeny Slashchev ${ }^{1}$ \\ Izhevsk State Technical University named after M.T. Kalashnikov, 7, Studencheskaya street, Izhevsk, 426069, Russian Federation \\ Perm National Research Polytechnic University, 29, Komsomolsky prospect, Perm, 614990, Russian Federation
}

\begin{abstract}
The article deals with the management methods of serial and experimental production based on the application of Petri net modelling methods in the operational and calendar planning of the manufacturing of machine-building products. The proposed management model, in contrast to existing analogues, allows making a set of management rules, analysing the relationships formed in the process of pilot production and its structure, as well as organizing optimal production according to the criterion to minimize the costs.
\end{abstract}

\section{Introduction}

The development of high-tech production and competitive products at enterprises and organizations of the military-industrial complex (hereinafter referred to as MIC) is of strategic importance for the Russian economy. On the one hand, this increases the country's defence capability and the level of development of industry technologies. On the other hand, it allows enterprises and organizations of the military-industrial complex to increase Russia's export potential by increasing its share in the international arms market.

However, the high achievements are based on serial and experimental production, which, as a result of repeated experimental production of machine-building and instrument-making products, allows working out the manufacturing technology. All this requires large material costs, which increase the cost of production, the size of which depends on many factors, including the lack of network infrastructure, which determines the degree of involvement of structural divisions in the management of the production process. In addition, accumulating the best practices of the domestic and foreign practice of using low-waste and non-waste technologies in the manufacture of competitive products and improving the processes of organizing serial and experimental production of defence industry enterprises the integration and management support is essential, taking into account the principles of lean production. This support is implemented in the form of a mechanism for managing serial and experimental production (hereinafter referred to as the SEP), organizational and economic set of tools that has its information basis, purpose, tasks, direct and feedback links with the objects of influence at the defence industry enterprises. [ЗОшибка! Источник ссылки не найден.] However, the organization of the coordinated application of this tool is based on human management decisions, which, combined with the insufficient digitalization of the analysed and managed production processes, does not allow obtaining the optimal organizational variation of the SEP with minimal costs. As a result, there is a need to apply special methods of operational and calendar planning of these processes that can provide the fastest and most cost-effective management decisions in the SEP. As a basis for the organization of such management, it is proposed to use the methods of Petri net modelling. Its application in the operative calendar planning based on the proposed prerequisites should cover the entire complex of processes and characteristics that reflect its essence, including the design of life cycle processes, the composition of the product, the sequence of manufacturing parts, changing the structure of the product, supply and technological operations.

\section{Prerequisites used for modelling operational and calendar planning using Petri Nets}

The main features of Petri nets [1] are the ability to reflect the parallelism, asynchrony, hierarchy of the simulated objects and lifecycle management processes.

A Petri net is formally represented as a set of the following form [3, с.4; 5 , с. 41Ошибка! Источник ссылки не найден.]:

$N=\left(P, T, F, H, \mu_{0}\right)$,

where $P$ is a finite non-empty set of positions (states or places);

$T$ is a finite non-empty set of transitions (events);

$F: P \times T \rightarrow\{0,1,2 \ldots\}$ - input function (input stream);

*Corresponding author: Dil-ma@ mail.ru 
$H: T \times P \rightarrow\{0,1,2 \ldots\}$ - output function (outgoing stream);

$\mu_{0}-$ initial marking.

The graphical structure of a Petri net is represented by a directed bipartite graph [4, c. 255], where the set of vertices is divided into two non-crossing sets (see Figure 1) - edges: input/output

The Petri Net (Figure 1) is characterized by the following sets:

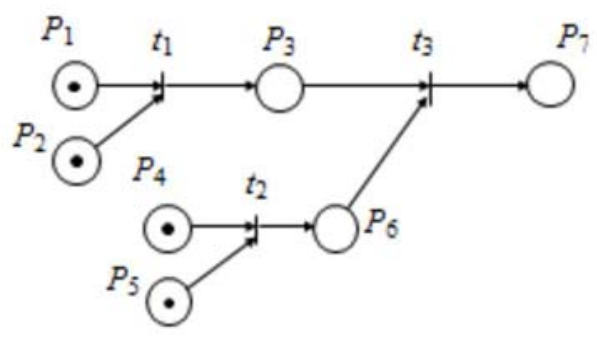

Figure 1. the Petri Nets

$P=\left\{P_{i} / i=1, \ldots, 7\right\}-$ positions; $T=\left\{t_{j} / j=1, \ldots, 3\right\}-$ transitions from one planning stage to another one;

$F=\left\{P_{1} t_{1}, P_{2} t_{1}, P_{4} t_{4}, P_{5} t_{4}, P_{6} t_{3}\right\}-$ arcs of outputs from plan positions;

$\mu_{0}=(1,1,0,1,1,0,0)-$ initial plan marking.

The transition from one marking to another is carried out by triggering transitions (or initiating transitions, i.e. starting work on a stage). The formal condition for triggering the transition compares the number of labels in $P_{i}$ with the number of arcs between $P_{i}$ and $t_{j}$. For a Petri net (see Figure 3), $t_{1}$ is considered an excited transition, since there are two labels at positions $P_{1}$ and $P_{2}$, and two arcs take off the positions.

$$
\mu\left(P_{0}\right)-F\left(P_{0} t_{j}\right) \geq 0, \forall_{P_{i}} \in P
$$

Starting the transition as a whole replaces the initial marking with a new one according to the following rule:

$$
\mu^{\prime}\left(P_{c}\right)=\mu\left(P_{c}\right)-F\left(P_{i} t_{j}\right)+H\left(t_{i} P_{i}\right), \forall_{P_{i}} \in P,
$$

where $P_{c}$ is the number of labels in one opposition, i.e., as a result of triggering the transition $t_{j}, F\left(P_{i} t_{j}\right)$ labels are excluded from all its output positions and $H\left(t_{i} P_{i}\right)$ labels are added to each input position.

The movement of the labels from one position to another shows the sequence of the process. These actions can be widely used, for example, when modelling the movement of orders in various management structures of organizations and production processes of operational and calendar planning.

When modelling the processes of operational and calendar planning, the production of a part using Petri Nets is mainly used in two ways.

The first method is characterized by the fact that the vertices-circles $P_{i}$ denote real-valued sets (parts, materials, tooling, equipment, etc.), and the transitions $t_{i}$ - energy connection-actions on them (see Figure 1).

The second method is characterized by the fact that the vertices-circles $P_{i}$ denote the state of real-valued sets and energy sets, and the transitions $t_{i}$-the boundaries of the beginning and end of the process (production stage) (see Figure 2.).

In the presented Petri net, the vertices $P_{3}$ and $P_{5}$ interpret the movements of the product in stages:

$P_{3}$ - completing the product with a subproducts $P_{1}$, transferring it to the production area and making the development batch $P_{4}$;

$P_{5}$ - package $P_{2}$ of the development batch $P_{4}$.

$P_{7}-$ shipment of the development batch $P_{4}$ with a set of permits $P_{6}$

Vertices $P_{1}$ and $P_{7}$ show the operational and calendar planning of the product production process

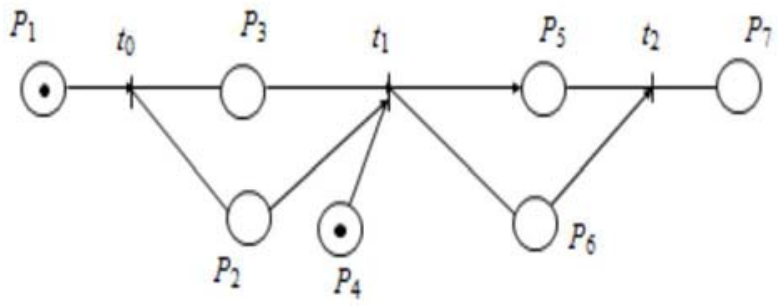

Figure 2.Petri Net when assembling two parts $\mathrm{P}_{1}$ and $\mathrm{P}_{4}$ using an industrial robot $\mathrm{P}_{2}$ and a press $\mathrm{P}_{6}$.

The mathematical model of the process (the movement of labels) can be represented by a matrix:

\begin{tabular}{|c|c|c|c|c|c|c|c|}
\hline & $P_{1}$ & $P_{2}$ & $P_{3}$ & $P_{4}$ & $P_{5}$ & $P_{6}$ & $P_{7}$ \\
\hline$\mu_{0}$ & 1 & 0 & 0 & 1 & 0 & 0 & 0 \\
\hline$\mu_{1}$ & 0 & 1 & 1 & 1 & 0 & 0 & 0 \\
\hline$\mu_{2}$ & 0 & 0 & 0 & 0 & 1 & 1 & 0 \\
\hline$\mu_{3}$ & 0 & 0 & 0 & 0 & 0 & 0 & 1 \\
\hline
\end{tabular}

A Petri net can also be represented as a time chain if all real-valued sets are discarded from it (Fig. 3):

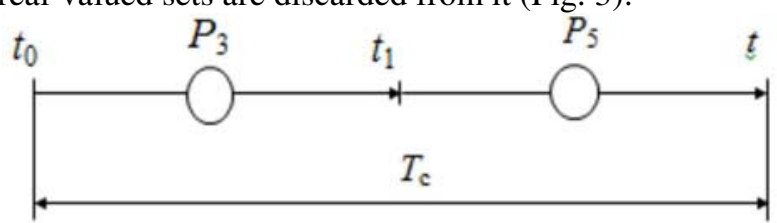

Figure 3. The temporal chain

From the temporal chain, the cycle time of the process $T_{\mathrm{C}}$ and the efficiency can be determined taking into account the influence of random deviations.

\section{The system of calculation of statements in operational and calendar planning}

Planning progress modelling is based on the following assumptions.

1. The intended service of the machine, drawings, specifications and technical conditions are mastered by the technologist.

2. The manufacture of the machine and its parts is provided. 
3. The subject of planning was compared with others to find a similar technology. No analogue can be found.

4. Typical loading of the enterprise with the use of equipment and without equipment is known.

One of the main tasks that must be solved in operational and calendar planning is the task of determining the sequence of production and the optimal division of the product according to the stages of preparation of assembly units of parts.

The main requirements for the plan installation sequence are the terms of time limits and access restrictions. The terms of the time limit are determined by the allocation of the boundary terms of the contract and the links with the manufacture of other products.

When planning, the condition for restricting the access of one part (product) of the planned batch to another ends with the relation part $X_{1}$ restricts the access of part $X_{2}$ to the place of manufacturing: $X_{1}\langle\rangle X_{2}$, where \langle\rangle is the sign of the restriction relation.

The restriction in the movement of production in all directions of some parts (products) by others means that there is a movement restriction ratio between the items: $\mathrm{X}_{1}\langle\rangle \mathrm{X}_{2}$.

The main requirements for the planning procedure based on the conditions of time limits and access are expressed in the following provisions:

1. If one part (product) restricts another, then it is assigned to the base and installed earlier than the one for which it is the base. Otherwise, this provision can be formulated as follows: if one of the parts (product) is the base, then it is installed in the plan of the first:

$$
\frac{a_{1} \vee a_{2},\left(a_{2}=\mathrm{O}_{1} \rightarrow b_{i} \& \mathrm{O}_{j}\right)}{a_{2}<a_{1} .},
$$

2. If one part (product) restricts access to the production of another, then the limited part (product) is installed in the plan before the one that restricts it:

$$
\left(a_{1}\left\langle>a_{2}\right) \rightarrow\left(a_{2}<a_{1}\right) .\right.
$$

3. If there is a set of parts (products), they are identified as one part (product) and they are installed and planned simultaneously:

$$
\left(a_{1}+a_{2}+a_{3}=\mathrm{K}\right) \rightarrow\left(a_{1} \& a_{2} \& a_{3}=\mathrm{C}\right),
$$

where $\mathrm{K}$ is a set; $\mathrm{C}$ is the connection of the prefabricated product to the plan.

4. If the part (product) is installed in the plan with the basic part (product), then initially it is focused on the complexity of manufacturing relative to the basic one, and then it is included in the operational and calendar planning:

$$
\mathrm{I} \rightarrow \mathrm{B} \& \mathrm{P},
$$

where I is the installation of the part in the plan relative to the base one.

All of these provisions are implemented only if the terms and access restrictions are defined. [2]

\section{Basic rules for modelling a production plan using information and computing systems}

Based on the evaluation of statements in the design of operational and calendar planning, a new grammar of algebraic expressions is revealed, which defines the rules for constructing formulas from planning objects using operation signs and separators. The main actions that interpret the planning processes with propositional variables, signs of addition, subtraction, and transformation techniques are considered.

In the planning algebra, the regularities and rules for constructing algebraic expressions from the order execution progress and its transformation are revealed, while the order execution sequence must be preserved and the number of actions determined.

The main regularities of the algebra of operationalcalendar planning of machine production are as follows:

- commutativity (permutability):

$$
3 a_{1}+2 a_{2}+a_{3}=2 a_{2}+3 a_{1}+a_{3},
$$

where $a$ is the propositional variables ( 0 or 1 ) denoting the name of the parts in the order with the indication of the product number in the index, and the coefficients denote the priority of the order of manufacture;

- distributivity (distributiveness):

$$
\begin{gathered}
2\left(2\left(2 a_{1}+a_{2}\right)+a_{3}\right)+a_{4}=2\left(4 a_{1}+3 a_{2}+a_{3}\right)+a_{4}= \\
=6 a_{1}+5 a_{2}+3 a_{3}+a_{4},
\end{gathered}
$$

where in the formulas, when opening the brackets, the coefficients are not multiplied, but added, which is a difference from the traditional law of distributivity;

- anti-associativity:

$$
3 a_{1}+\left(2 a_{2}+a_{3}\right) \neq\left(3 a_{1}+2 a_{2}\right)+a_{3} .
$$

The rules for constructing formulas using operation signs and separators also have their characteristics, for example: addition and subtraction depend on the ratio of the order of concentration and differentiation of actions during planning.

The addition or production of an order with a strict sequence is carried out by the production of products:

a) different:

$a_{1}<\left(a_{1}+a_{2}\right)<\left(a_{1}+a_{2}+a_{3}\right) \rightarrow 3 a_{3}+2 a_{2}+a_{3} ;$

b) identical:

$$
\left(3 a_{1}+2 a_{1}+a_{1}\right) \rightarrow 3,3 a_{1},
$$

where the coefficient 3.3 shows both the number of actions and products.

If the same orders in the plan have a coefficient before the brackets indicating the order of production, then only the integer part of the number changes, for example: 


$$
5\left(3 a_{1}+2 a_{1}+a_{1}\right)=8,3 a_{1}
$$

If it is necessary to include positions in the production plan, consisting of a strict sequence of new products, the differentiation is determined by the implication:

$$
a_{1}<2\left(a_{1}+a_{2}\right)+\left(a_{1}+a_{2}+a_{3}\right) \rightarrow 2\left(2 a_{1}+a_{2}\right)+a_{3} .
$$

The subtraction of the product at the concentration or the exclusion of the product from the plan in a strict sequence is modelled by the formula:

$$
\begin{aligned}
& \left(3 a_{1}+2 a_{2}+a_{3}\right)-a_{3}=a_{3} \oplus\left(4 a_{1}+3 a_{2}\right) \\
& -3 a_{2}=a_{3} \oplus 3 a_{2} \oplus 5 a_{1} .
\end{aligned}
$$

Subtraction, which simulates the process of excluding a product from the plan when differentiating in any sequence, is characterized by the following transformation:

$$
\begin{aligned}
& \left(2\left(2 a_{1}+a_{2}\right)+a_{3}\right)=\left(4 a_{1}+3 a_{2}+a_{3}\right) \\
& -a_{3}=a_{3} \oplus\left(5 a_{1}+4 a_{2}\right)-4 a_{2}= \\
& =a_{3} \oplus 4 a_{2} \oplus 6 a_{1} .
\end{aligned}
$$

It should be noted that when subtracting, the products do not disappear, but occupy the initial position in the disassembled form with coefficients indicating the number of actions.

The product or synchronous parallel planning of identical parts is expressed by implication:

$$
\left(a_{1} \& a_{1} \& a_{1} \rightarrow a^{3}\right)
$$

The introduction of an absolute value denoting the removal of all separators and priorities of the planning order is determined by the expression:

$$
\left|\left(2\left(2 a_{1}+a_{2}\right)+a_{3}\right)\right|=\left|\left(4 a_{1}+3 a_{2}\right)+a_{3}\right|=a_{1}+a_{2}+a_{3} .
$$

By entering an absolute value, the number of items in the plan is determined by the number of actions on the item in the plan.

All these principles are interdependent and mutually dependent. They reflect objective and stable relationships that are manifested in operational and calendar planning.

This is followed by the calculation of technical and economic indicators of the operational and calendar planning process.

On the basis of complex modelling, the following technical and economic indicators are calculated:

1. From the modelling of the evaluation of statements, the type of planning is determined as sequential.

2. When drawing up the scheme, the following parameters were easily identified: the sequence of operations, the composition of assembly units and sets of parts, as well as the time of operations.
3. When simulating the process with the help of a diagram, the following parameters are determined:

a) The load factor of jobs is determined according to the formula:

$$
p_{l}=\sum_{i=1}^{m} T_{i} / T_{c i},
$$

where $\sum T_{i}$ is the total time of formation $(t)$ of items,

$T_{c i}$ - production time $(\boldsymbol{t})$ of items.

For each workplace of the production line, the coefficient value will be:

$$
\begin{gathered}
\mathrm{pl}=60 / 65=0.9, \mathrm{p} 2=80 / 100=0.8, \\
\mathrm{p} 3=40 / 110=0.38 .
\end{gathered}
$$

b) Maximum number of sets of items in the workplace (work in progress) $\mathrm{N}=3$ (see line $\mathrm{tl}$ );

c) The average volume of work in progress $(p)$ for the entire line is calculated using the formula:

$$
n=1 / T \sum_{i=1}^{m} t_{i}{ }^{*} n_{i}
$$

where: $\mathrm{T}$ is the simulation period,

ti- the time during which there were $\mathrm{i}$ items at the workplace. For the initial approximation:

$$
\mathrm{n} 1=1 / 65 *(30 * 1+25 * 2+5 * 2)=90 / 65=1.5 \text { items }
$$

For the initial approximation:

$$
\mathrm{n} 2=1 / 100 *(60 * 1+30 * 2)
$$

d) Downtime in the workplace due to irrational differentiation of technological operations of operational and calendar planning occurs when the fourth product is being formed. Their value can be determined by the formula:

$$
\mathrm{P}=(\operatorname{timax}-\mathrm{t}(\mathrm{i}+1)) * \mathrm{rn},
$$

where timax is the maximum release time or clock cycle, in particular for this example, timax $=20 \mathrm{~min}$,

$\mathrm{t}(\mathrm{i}+1)$ - time to operate on the workstations, except for the first operation,

$\mathrm{m}-$ the number of manufactured products.

For this line, the average amount of downtime due to irrational differentiation of operational and calendar planning is equal to:

$$
\mathrm{Rsr}=(\operatorname{timax}+\mathrm{t}(\mathrm{i}+1) * \mathrm{~m} / \mathrm{Tc}
$$

or

$$
\mathrm{Rsr}=(20-10) * 4 / 110=40 / 110=0.4 \mathrm{~min} .
$$

Note that the amount of downtime due to irrational differentiation of operational and calendar planning should tend to zero.

e) The average length of the queue of sets of parts waiting to be assembled and connected

$$
L=1 / T_{i} \sum_{i=0}^{L} t_{i} * l_{i}
$$


where: $t_{i}$ - the time during which there were $L_{i}$ items in the queue.

For this line, queues are formed at the first and third workplace

$$
\begin{gathered}
\mathrm{Ll}=1 / 65 *(25 * 1+5 * 2)-30 / 65=-0,25 \mathrm{~L} 3=1 / 100 *(30 * 1)=0.3 \\
\text { items }
\end{gathered}
$$

f) The waiting time for the sets of items in the queue will be:

$$
W=1 / m \sum_{i=1}^{m} \boldsymbol{W}_{i},
$$

where: $\mathrm{w}$ - is the waiting time for a set of product items.

For this line, it is equal to:

$$
\begin{gathered}
\mathrm{W} 1=1 / 4 *(5+10+20)=35 / 4=8,9 \mathrm{~min} . \\
\mathrm{W} 2=1 / 4 *(30)=7.5 \mathrm{~min} .
\end{gathered}
$$

Production line capacity:

\begin{tabular}{|c|c|c|c|}
\hline No & Indicators & $\begin{array}{l}\text { Calculation } \\
\text { formulas }\end{array}$ & $\begin{array}{l}\text { Quantitati } \\
\text { ve value }\end{array}$ \\
\hline 1 & $\begin{array}{l}\text { Coefficient } \\
\text { downloads }\end{array}$ & $\mathrm{n} 0=\mathrm{n} 1+\mathrm{n} 2+\mathrm{n} 3$ & 0.6 \\
\hline 2 & $\begin{array}{l}\text { Release cycle } \\
\text { products }\end{array}$ & $\mathrm{tB}=\mathrm{timax}$ & $20 \mathrm{~min}$ \\
\hline 3 & Efficiency & $\mathrm{Ph}=\mathrm{m} * 60 / \mathrm{Tc}$ & $2.2 \mathrm{pcs} / \mathrm{h}$ \\
\hline 4 & $\begin{array}{l}\text { Average volume of - } \\
\text { work in progress }\end{array}$ & $\mathrm{n}=\mathrm{n} 1+\mathrm{n} 3 / 2$ & 1.35 sets \\
\hline 5 & $\begin{array}{l}\text { Length of the queue of } \\
\text { sets of parts }\end{array}$ & $\mathrm{Lsr}=\mathrm{Ll}+\mathrm{L} 3 / 2$ & 0,28 sets \\
\hline 6 & Queue waiting time & $\begin{array}{c}\mathrm{Wsr}=\mathrm{Wl}+\mathrm{W} 3 / \\
2\end{array}$ & $8.2 \mathrm{~min}$. \\
\hline 7 & $\begin{array}{l}\text { Average value of } \\
\text { downtime }\end{array}$ & $\begin{array}{c}\text { Rsr }=(\text { tirnax }+ \\
\mathrm{t}(\mathrm{i}+\mathrm{l}) \mathrm{m} / \mathrm{Tc}\end{array}$ & $0,4 \min$. \\
\hline 8 & $\begin{array}{c}\text { Product output volume } \\
\text { units per cycle }\end{array}$ & $\mathrm{m}$ & 4 pcs. \\
\hline 9 & $\begin{array}{c}\text { The complexity of } \\
\text { manufacturing a single } \\
\text { product }\end{array}$ & $t=\sum^{m} t i$ & $\begin{array}{c}0.91 \\
\text { hours }\end{array}$ \\
\hline
\end{tabular}

$$
\mathrm{N}=\mathrm{m} / \mathrm{Tc}=4 / 110=0.036 \mathrm{pcs} / \mathrm{min} .
$$

All the main technical and economic indicators are summarized in Table 1.

Table 1. Production line indicators

It should be noted that to build the considered model, it is not necessary to know the physical nature of the process.

\section{Conclusion}

The article considers the author's approach to managing the operational and calendar planning of the SEP of a machine-building or instrument-making product based on the use of Petri Nets. The purpose of this control is to obtain a motion matrix that allows optimizing the implementation of the plan in dynamics based on the analysis of system parameters interrelated processes of operational and calendar planning of the SEP.

This author's approach develops the possibility of automating the process

of planning at the stage of serial and operational production, allows minimizing the number of human errors in the process of operational and calendar planning and reducing the amount of work in progress, which is covered by errors in calculations. The result of the application of the author's approach to management is also a reduction in the consumption of material resources in the process of manufacturing experimental samples of machine-building and instrument-making products.

\section{References}

1. D.M. Malikova, E.S. Slashchev, S.A. Shilyaev, R.F. Shaikhov, V.G. Osetrov Journal of Advanced Research in Dynamical and Control Systems, 12 (2 Special Issue), 391-395, (2020)

2. D.M. Malikova, E.S. Slashchev, E.P Istomin., M.R. Vagizov, O.E. Kolbina IOP Conference Series: Earth and Environmental Science, 507(1) 012018 (2020)

3. D. V. Isaev Financial analytics: problems and solutions. 20 (254) 2-12 (2015).

4. P. V. Skorodumov Economic and social changes: facts, trends, forecast 4(34) 253-259 (2014)

5. A. A. Khanova, A. A. Muntyanova, K. I. Averyanova Science Bulletin of the NSTU 71(2), 39-58, (2018) 